in Drosophila as due to a lagging sex-chromosome. As a full account of his researches has not yet been published, I am unable to undertake the task of harmonizing it with what I conceive to be the conditions in the Formicidæ.

\title{
A MALFORMED LEPTINOTARSA DECEMLINEATA.
}

\section{By C. L. Metcalf, \\ Ohio State University.}

The two accompanying illustrations show an interesting and peculiar malformation of a specimen of the Colorado potato beetle. The specimen was collected by Mrs. Cleo F. Metcalf at Orono, Maine, August 17, 1916. It was taken in company with many normal individuals feeding upon potato. Unfortunately its peculiar condition was not noted until it had been killed. A prolonged search failed to reveal any other specimens in any way abnormal. The chief purpose in describing it here is to record for the curious naturalist, who does not lack a sense of humor, a freakish, though not uncomely, product of one of nature's sportive moods.

The visible abnormality consists of a deep, V-shaped excision of each elytron extending from the apex to about the basal third of the normal elytron. The elytra are a little foreshortened; the middorsal line is nearly straight in side view; and the usual convexity

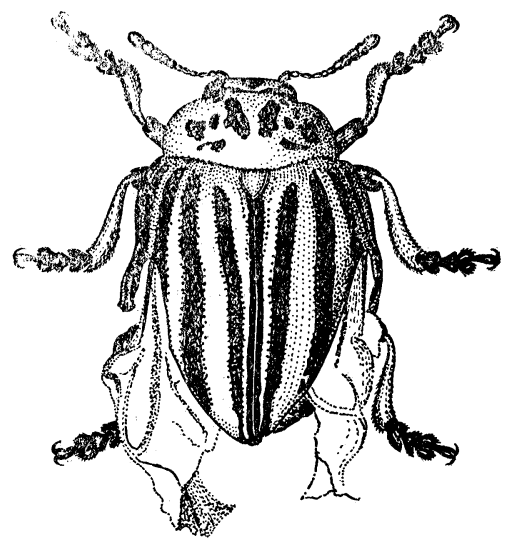
covering the tip of the abdomen is entirely wanting, leaving the abdomen exposed from behind.

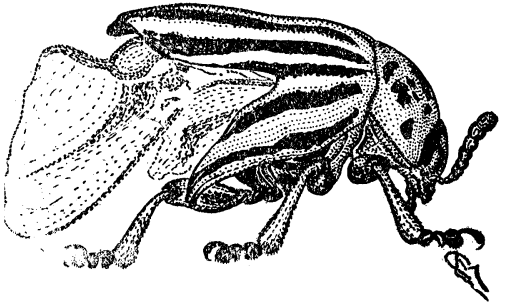

Fig. 1. Malformed Leptinotarsa decemlineata, showing anomaly in structure and pattern of the elytra; below, same in lateral view. About three times natural size. 
The two forks of the elytron formed by the excision are unequal, the median fork being about twice as wide at base and somewhat longer. The lateral fork is bent sharply ventro-laterad and is sinuate, its tip especially curving away from the excision. The apex of the excision is broadly rounded; its sides are convex inward.

The color markings are as little disturbed as could well be,- - the black suture and five black stripes on each elytron being readily recognizable. The first and second stripes run nearly their full length. The third runs a little mediad of the apex of the excision, shows a slight tendency to fork to the outer prong, and margins the inner prong about halfway to its apex, gradually attenuating to a point. Its course is such as not to encroach upon the normal width of the intervening yellow stripe. The second and third stripes do not, therefore, unite toward the apex as in the typical individual. The fourth black stripe has a slightly different position on the two elytra. On the left it runs just laterad of the apex of the excision margining the outer prong with black, within, almost to its apex; gradually narrowing. On the right elytron the fourth stripe curves abruptly about three millimeters from the humerus, eluding the margin of the excision over its basal half, thence terminating in normal width; after which the margin is again yellow. The fifth stripe runs about a normal course with respect to the margin of the elytron. This stripe and the yellow interval between it and the fourth stripe are somewhat abnormally widened about mid-length.

The most noteworthy feature of the insect is the very close symmetry of the two malformed elytra. Besides the slight difference in the course of the fourth stripe, the only discrepancy is in the length of the elytra at the suture; the left one exceeds the right by about a half millimeter.

It is interesting to speculate as to the probable cause of such development. Mere mechanical injury or pressure would seem to be an inadequate explanation, unless presumed to occur at a very early stage. The close similarity of the anomaly in the two wings seems to me to point to a deep-seated, physiological disturbance, the nature of which I am entirely unable to conjecture. ${ }^{1}$

It is unfortunate that the specimen was not noted in time to make possible extensive observations of its behavior, and that an examination of the internal structures of the fresh specimen was neglected. The specimen is in the collection of the writer.

1 See Brues, Charles T., The Structure and Significance of Vestigial Wings among Insects. Biol. Bull., Vol. IV., No. 4, March, 1903, pp. 179-190. 

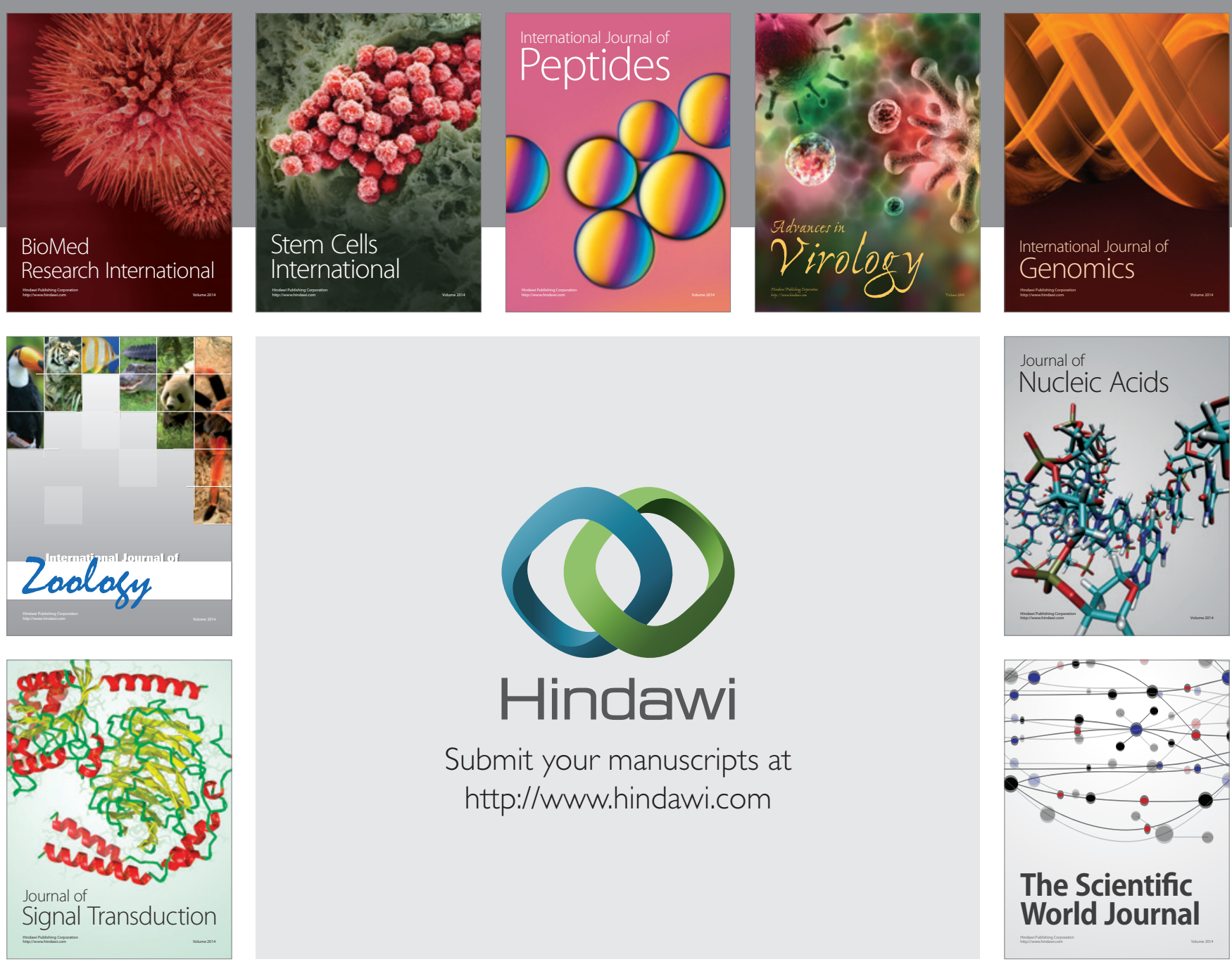

Submit your manuscripts at

http://www.hindawi.com
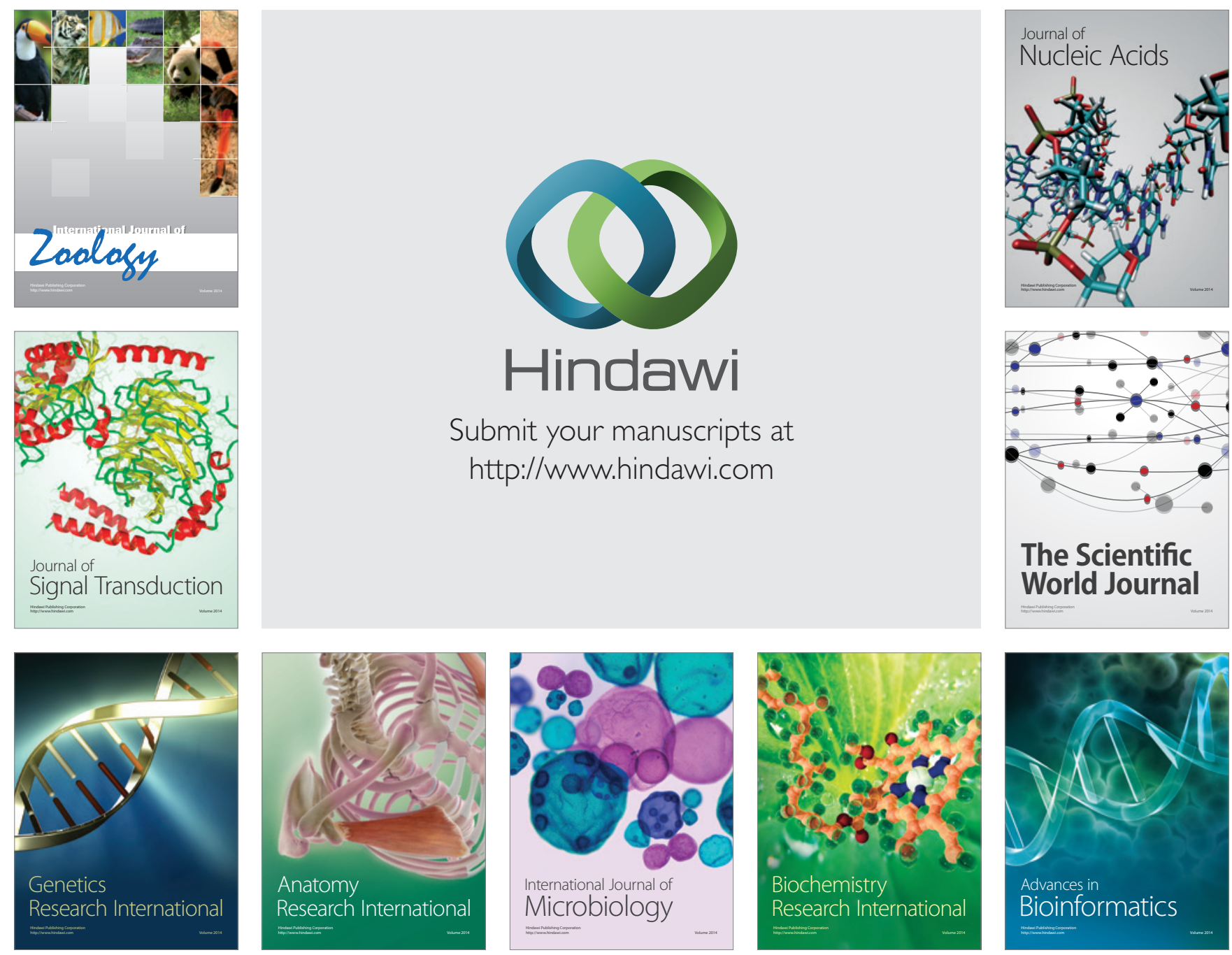

The Scientific World Journal
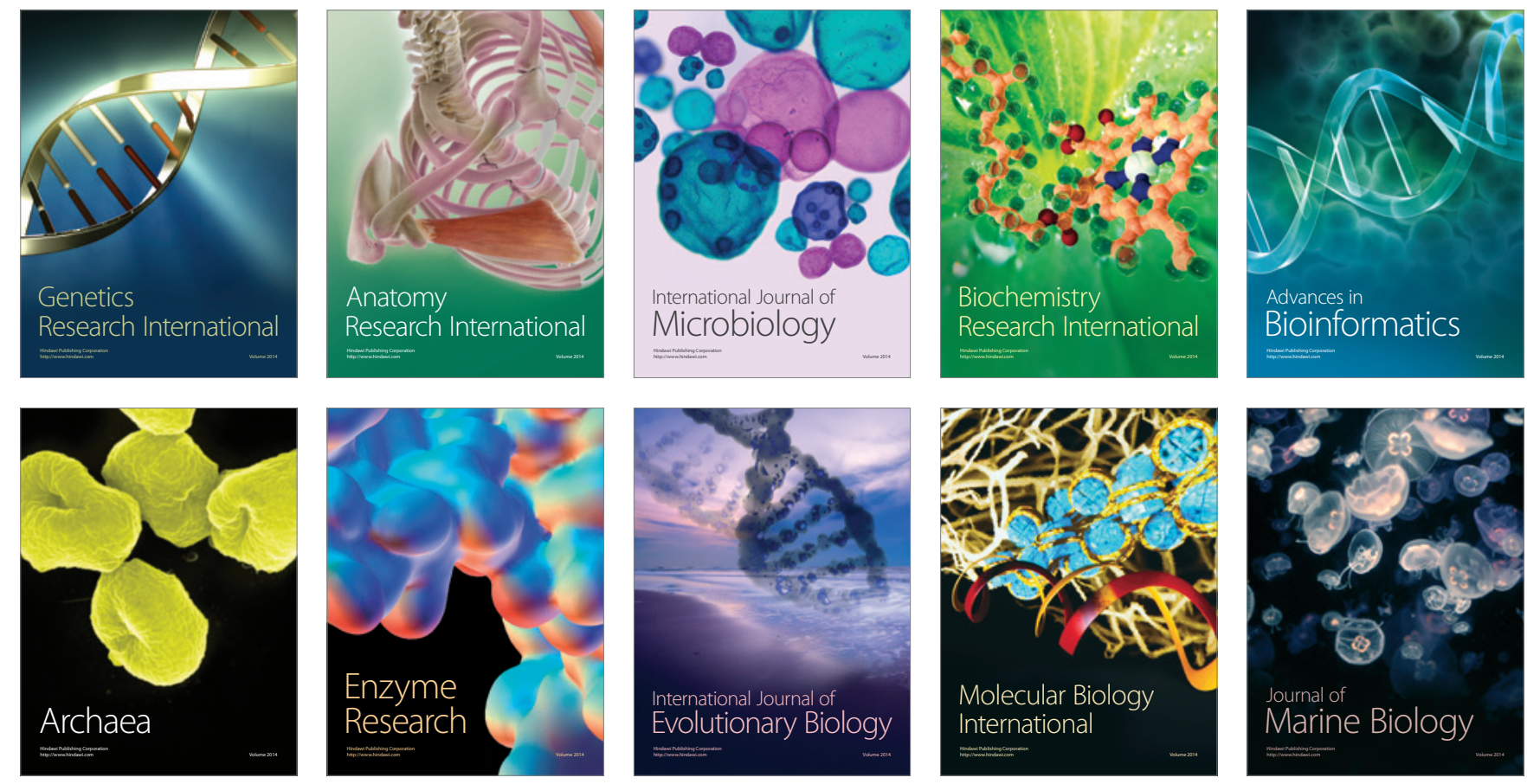